\title{
Oxidative and Nitrosative Stress in Oral Squamous Cell Carcinoma
}

\author{
Gesche Frohwitter $^{\mathrm{a}} \quad$ Ornella Lisa Zimmermann $^{\mathrm{b}} \quad$ Kilian Kreutzer $^{\mathrm{c}}$ \\ Christian Doll ${ }^{c}$ Carsten M. Rendenbach ${ }^{c}$ Henrik Dommisch ${ }^{d}$ \\ Klaus-Dietrich Wolff ${ }^{b}$ Marco R. Kesting ${ }^{a}$ Max Heiland ${ }^{c}$ Steffen Koerdt ${ }^{c}$ \\ ${ }^{a}$ Department of Oral and Maxillofacial Surgery, Friedrich Alexander University, Erlangen, Germany; ${ }^{b}$ Department of \\ Oral and Maxillofacial Surgery, Technical University of Munich (TUM), Munich, Germany; ${ }^{\circ}$ Department of Oral and \\ Maxillofacial Surgery, Charité - Universitätsmedizin Berlin, Corporate Member of Freie Universität Berlin, \\ Humboldt-Universität zu Berlin, and Berlin Institute of Health, Berlin, Germany; ${ }^{\mathrm{d}}$ Department of Periodontology and \\ Synoptic Dentistry, Charité - Universitätsmedizin Berlin, Corporate Member of Freie Universität Berlin, \\ Humboldt-Universität zu Berlin, and Berlin Institute of Health, Berlin, Germany
}

\section{Keywords}

Oxidative stress · Nitrosative stress · RONS · Oral cancer ·

Oral squamous cell carcinoma

\begin{abstract}
Introduction: The incidence of oral squamous cell carcinoma (OSCC) shows a constant increase, while the long-term outcome remains poor over the last decades. Radical oxygen and nitrogen species (RONS) - initially released by carcinogens, such as alcohol and tobacco, and later maintained by the tumor microenvironment - appear to be strongly associated to chronic inflammation, tumor induction, progression, and metastatic spread. The aim of this study was to evaluate the role of oxidative and nitrosative stress in primary OSCC compared to healthy tissue specimens and to identify their impact on tumor carcinogenesis. Materials and Methods: In this basic research study, tissue samples of 30 patients with primary OSCC were evaluated for the expression of pAKT, pERK, 3-NT, NOS1, NOS3, MAPK1, and IP-8 by immunohistochemistry and RT-PCR and compared to those of a healthy control group ( $n=30$ ). Results: The results showed a significantly increased expression of pAKT $(p<0.001), \operatorname{pERK}(p=$ $0.01), 3-\mathrm{NT}(p=0.039), \operatorname{NOS1}(p=0.025), \operatorname{NOS3}(p=0.046)$,
\end{abstract}

karger@karger.com www.karger.com/cto

Karger $\frac{1}{\%}$

GOPEN ACCESS
(C) 2020 The Author(s)

Published by S. Karger AG, Basel

This is an Open Access article licensed under the Creative Commons Attribution-NonCommercial-4.0 International License (CC BY-NC) (http://www.karger.com/Services/OpenAccessLicense), applicable to the online version of the article only. Usage and distribution for commercial purposes requires written permission. and MAPK1 $(p=0.032)$ in OSCC tissue samples compared to healthy controls. Conclusion: The results of this study prove the tested stable degradation products to be suitable for the detection of RONS in OSCC. Moreover, the significantly increased expression underlines the role of RONS in carcinogenesis of OSCC, suggests specific mechanisms of detection, and anticipates supplementary research.

(c) 2020 The Author(s)

Published by S. Karger AG, Basel

\section{Introduction}

Oral cancer, of which most are histologically defined as oral squamous cell carcinomas (OSCC), accounts for $4 \%$ of all malignancies in men and $2 \%$ of those in women [Cunningham et al., 1986]. Moreover, it is a global health problem with approximately 400,000 newly diagnosed cases worldwide, accounting for the sixth most common malignancy in the world [Lingen et al., 2008]. Etiologically, chronic exposure to carcinogens such as tobacco, alcohol, oncogenic viruses, and inflammation plays an important role. Genetic alterations of tumor suppressor genes and oncogenes result in uncontrollable tumor growth. The combination of tobacco and alcohol abuse, but also tobac- 
co exposure alone, is by far the most potential carcinogen that leads to OSCC [Talamini et al., 2002]. On a cell-based level, tobacco smoke exposes the oral mucosal epithelium to large amounts of toxic reactive oxygen and nitrogen species (RONS) such as hydrogen peroxide $\left(\mathrm{H}_{2} \mathrm{O}_{2}\right)$ and other hydroxyl radicals. Physiological antioxidant mechanisms of the mucosa can be overwhelmed and exceeded. However, this results in major interrelated impaired cell mechanisms such as DNA strand breaks, membrane damage, and damages of other specific tumor suppressor genes that lead to disease progress [Johnson, 2001]. RONS such as the superoxide anion $\mathrm{O}_{2}{ }^{-}$, the hydroxyl radical $\mathrm{OH} \bullet$, hydrogen peroxide $\left(\mathrm{H}_{2} \mathrm{O}_{2}\right)$, nitric oxide $(\mathrm{NO} \cdot)$, and the peroxynitrite anion $\mathrm{ONOO}^{-}$are highly reactive and therefore potentially harmful [Droge, 2002; Valko et al., 2007]. Their role in tissue alterations following radiation therapy and autologous bone grafting has been subject to immunohistochemical studies using well-established protocols [Koerdt et al., 2014; Koerdt et al., 2017b]. However, for immunohistochemical staining, stable degradation products are used, as RONS have a comparatively short life and extreme responsiveness [Droge, 2002].

The nitration of tyrosine is catalyzed and mediated by RONS such as $\mathrm{ONOO}^{-}$and $\mathrm{O}_{2}^{-}$. 3-Nitrotyrosine (3-NT), as a newly formed stable nitrated protein, acts as a biomarker of oxidative and nitrosative stress. Increased expressions have been described in atherosclerosis, lung disease, inflammation, and after transplantation [Skinner et al., 1997; Mohiuddin et al., 2006]. During prostaglandin $\mathrm{H}_{2}$ synthase, cyclooxygenase 8-isoprostane (8-IP) is formed as a byproduct of lipid oxidation catalyzed by free radicals. This makes 8-IP a stable and specific marker in immunohistochemical analysis of oxidative stress. Other studies have shown that 8-IP acts as a highly potent vasoconstrictor and thromboxane/endoperoxide receptor antagonist [Lehnig, 1999]. Phosphorylated extracellular signal-regulated kinase (pERK) is part of the mitogen-activated protein kinase (MAPK) network. RONS such as $\mathrm{ONOO}^{-}$and $\mathrm{H}_{2} \mathrm{O}_{2}$ activate the MAPK pathway. However, other working groups have described increased levels of pERK in melanomas, gliomas, bladder, endometrial, and esophageal cancers [El-Habr et al., 2010; Tasioudi et al., 2012]. Serine/threonine-specific protein kinase, also known as protein kinase $B$, plays a major role in the phosphoinositide-3 kinase (PI3K) pathway. Heat shock, hypoxia, UV- and gamma-radiation, and oxidative stress $\left(\mathrm{H}_{2} \mathrm{O}_{2}\right)$ are known to activate pAKT [Chen et al., 2001; Crossthwaite et al., 2002]. pAKT catalyzes the activation of endothelial nitric oxide synthase (NOS) in angiogenesis [Zeng et al., 2000]. The MAPK/ERK and PI3K/AKT pathways both play an important role in fundamental cell regulations. In terms of nitrosative stress, nitric oxide (NO) is considered to be a short-living radical involved in many important biological functions such as vasodilatation, immunoregulation, and neurotransmission. NO is produced by NOS, which exists in different isoforms: NOS1, known as neuronal NOS (nNOS), and NOS3, also referred to as endothelial NOS (eNOS), both being constitutively called cNOS, whose expression depends on intracellular calcium levels.

This current study aims to identify molecular pathways that might influence local tumor spread and to identify crosslinks between disease progress and the expression of oxidative and nitrosative stress. However, this complicated underlying network of cell-regulating mechanisms and the influence of oxidative and nitrosative stress have not been studied to this extent for OSCC so far. This current study might gain additional knowledge about pathways, turning points, and the molecular etiology of OSCC with special regards to the role of RONS.

\section{Materials and Methods}

\section{Participants}

All participants were informed extensively about this study and signed an informed consent form. Clinical data concerning parameters such as age, sex, tumor stage, and adjuvant therapies were obtained and documented. Based on parameters defined by the WHO, and used and applied in the German Federal Health Study 2006, smokers were divided into "heavy" smokers ( $\geq 20$ cigarettes per day), "moderate" smokers (11-20 cigarettes per day), and "light" smokers ( $<10$ cigarettes per day) [Schulze and Lampert, 2006]. Grouping according to pack-years was impossible due to insufficient documentation and the retrospective character of the study. Alcohol consumption was defined using a modified and simplified classification as described by Baker et al. [2002]. The definition comprised "daily or almost daily/very frequent" consumption ( $\geq 5$ times per week), "moderately frequent" consumption ( $<4$ times per week), as well as abstinence (no alcohol consumption). Additionally, alcohol consumption was subcategorized into consumption of beverages with high alcohol content ( $\geq 15 \%)$, moderate content (5-15\%), and low content (5\%). Alcoholism was defined as consumption of at least $60 \mathrm{~g}$ alcohol per day in males and $20 \mathrm{~g}$ per day in females. The combination of alcohol and tobacco was taken into consideration as well. Taking these specifications into account, 18 patients $(60 \%)$ were smokers and 15 patients (50\%) showed a pathological use of alcohol.

\section{Tissue Samples}

Tissue samples were collected during intraoral tumor resection $(n=30)$ and during routine oral surgical procedures in the healthy study population $(n=30)$. Specimens with approximate dimensions of $2 \times 10 \mathrm{~mm}$ were divided into two pieces under sterile conditions; one piece was stored in Allproctect ${ }^{\mathrm{TM}}$ solution $(\mathrm{N}, \mathrm{N}-\mathrm{di}$ - 
Table 1. Antibodies used for immunohistochemical staining

\begin{tabular}{lllll}
\hline Antibody & Species & $\begin{array}{l}\text { Con- } \\
\text { centration }\end{array}$ & Manufacturer & $\begin{array}{l}\text { Min } \\
\text { DAB }\end{array}$ \\
\hline Nitrotyrosine & Rabbit & $1: 500$ & Chemicon, USA & 15 \\
Isoprostane & Goat & $1: 1,500$ & NatuTec, Germany & 10 \\
pERK & Goat & $1: 400$ & Sigma-Aldrich, USA & 30 \\
pAKT & Rabbit & $1: 500$ & Upstate, USA & 20 \\
\hline
\end{tabular}

DAB, diaminobenzidine.

methylacetamide; Qiagen, Germany) at $-80^{\circ} \mathrm{C}$, whereas the other half was placed in $4.5 \%$ buffered formalin for immunohistochemical staining.

\section{Immunohistochemistry}

Tissue specimens were embedded in paraffin and cut into 5 - $\mu$ m-thick sections. According to local standard protocols, immunohistochemical staining was performed. The specimens were deparaffinized in xylene and rehydrated in a graded alcohol series. After having been washed with $0.05 \mathrm{M}$ Tris-buffered saline (TBS) and treated with $\mathrm{CH}_{3} \mathrm{OH}$ and $\mathrm{H}_{2} \mathrm{O}_{2}$ to block endogenous peroxidase in order to avoid false positive results, the samples were treated with ammonium chloride and Triton X (Schwarz/Mann Biotech, USA) in TBS to increase the permeability of the cell walls. Incubation in 5\% bovine serum albumin (PAA Laboratories, UK) was followed by treatment with the primary antibody in a pretested concentration (Table 1). After incubation with the primary antibody, incubation with the secondary antibody (Vector Laboratories Inc., USA) for $60 \mathrm{~min}$, and washes with TBS, streptavidin biotinylated horseradish peroxidase complex (Amersham Biosciences, Germany) was added to the sections. A diaminobenzidine (DAB) solution (Sigma-Aldrich, USA) was used for development, which was monitored and standardized for all stainings using the specific antibody. Negative controls, in which the primary antibody was omitted, were treated alike otherwise. Immunohistochemical staining was analyzed using a microscope, and images of 10 regions of interest were captured with a digital camera (Nikon, Germany). All specimens were evaluated by 2 independent and specially trained investigators. At the time of analysis, the investigators were blinded. The positivity (POS) of the immunostaining, measured as the percentage of cells with a color reaction due to the staining against the used antibody, was assessed using a five-level scale in which negative to 0 indicated $0-5 \%$ positive cells, 1 indicated $>5-10 \%$ positive cells, 2 indicated $>10-50 \%$ positive cells, 3 indicated $>50-80 \%$ positive cells, and 4 indicated $>80-100 \%$ positive cells. Intensity (I) was graded as follows: $0=$ none,$+=$ weak, $++=$ moderate, and $+++=$ strong/intense. For all mean values, the immunoreactive score was calculated $\left(\left[\left(\mathrm{I}_{\text {Investigator } 1}+\mathrm{I}_{\text {Investigator } 2}\right)\right.\right.$ $12] \times\left[\left(\mathrm{POS}_{\text {Investigator } 1}+\mathrm{POS}_{\text {Investigator } 2}\right) / 2\right]$; minimum value $=0$; maximum value $=12)$ [Remmele and Schicketanz, 1993].

\section{$R T-P C R$}

RT-PCR was run on individual samples. Therefore, ribonucleic acid (RNA) isolation was performed using the RNeasy ${ }^{\circledR}$ Protect mini kit (Qiagen). Beforehand, tissue samples were comminuted using a rotor-stator system (Miccra; ART Labortechnik, Germany)
Table 2. Primer sequences of examined genes

\begin{tabular}{ll}
\hline Gene & Sequence $5^{\prime}$ to $3^{\prime}$ \\
\hline $\begin{array}{l}\text { MAPK } \\
\text { Forward } \\
\text { Reverse }\end{array}$ & CAGTGGGATGGAATTGAAAG \\
NOS1 & AGCAGAAGGAATGAGTGTGC \\
Forward & \\
Reverse & GACTGTTGAGATGGAAGAAC \\
NOS3 & ATCTTCCTGTCTCCGAGGCG \\
Forward & GTGATGGCGAAGCGAGTGAAG \\
Reverse & CCGAGCCCGAACACACAGAAC \\
\hline
\end{tabular}

and ultrasonification. After measuring the amount of extracted RNA by means of a biophotometer (Eppendorf, Germany), $1 \mu \mathrm{g}$ isolated RNA was used for reverse transcription. Reverse transcription was performed according to the protocol of the SuperScript ${ }^{\mathrm{TM}}$ First Strand Synthesis System (Invitrogen, Germany). Random primers were used for reverse transcription. For RT-PCR, $2 \mu \mathrm{L}$ cDNA sample, $2 \mu$ L LightCycler ${ }^{\circledR}$ FastStart DNA Mater SYBR Green I reaction mix (Roche, Germany), $1 \mu \mathrm{L}$ forward and reverse primers $\left(0.5 \mu \mathrm{mol} \mathrm{L}^{-1}\right), 1.6 \mu \mathrm{L} \mathrm{MgCl}_{2}\left(3 \mathrm{mmol} \mathrm{L}^{-1}\right)$, and $12.4 \mu \mathrm{L}$ RNase-free water, resulting in a volume of $20 \mu \mathrm{L} / \mathrm{sample}$, were analyzed using the LightCycler ${ }^{\circledR} 1.0$ system (Roche). Primer specificity was tested using electrophoretic separation of the PCR product. Primer specifications are shown in Table 2. Amplification algorithms were as follows: $10 \mathrm{~min}$ at $95^{\circ} \mathrm{C}, 40$ cycles of $15 \mathrm{~s}$ at $94^{\circ} \mathrm{C}$, $10 \mathrm{~s}$ at $60^{\circ} \mathrm{C}$, and $10 \mathrm{~s}$ at $72^{\circ} \mathrm{C}$. A melting curve analysis was recorded in order to test for cDNA fragment consistency. The amount of RNA was automatically calculated by comparison of measured threshold cycles with standard curves and normalized with glyceraldehyde 3-phosphate dehydrogenase (GAPDH) as a housekeeping gene. A no template control was included in each run. All amplifications were carried out in triplicates, in which every sample was run 3 times and the results were averaged afterwards.

\section{Statistical Analysis}

All data were analyzed using $\mathrm{IMB}^{\circledR}$ SPSS ${ }^{\circledR}$ for Mac (version 24.0; IMB Corp., USA). Means and SD were calculated, and tests of significance were performed. For normally distributed values, Student's $t$ test was performed. For continuous values, the MannWhitney U test was used. Prior to Student's $t$ test, Levene's test was used to assess equality of the samples. Statistical significance was adapted to multiple testing. Statistical significance was defined as $\alpha=0.05$.

\section{Results}

\section{Patients}

A total of 30 patients with histologically proven OSCC were included in the current study: 22 (73.3\%) were male, $8(26.7 \%)$ were female. The median age was $58 \pm 9$ years (range: 44-76). The location of the OSCC was as follows: 

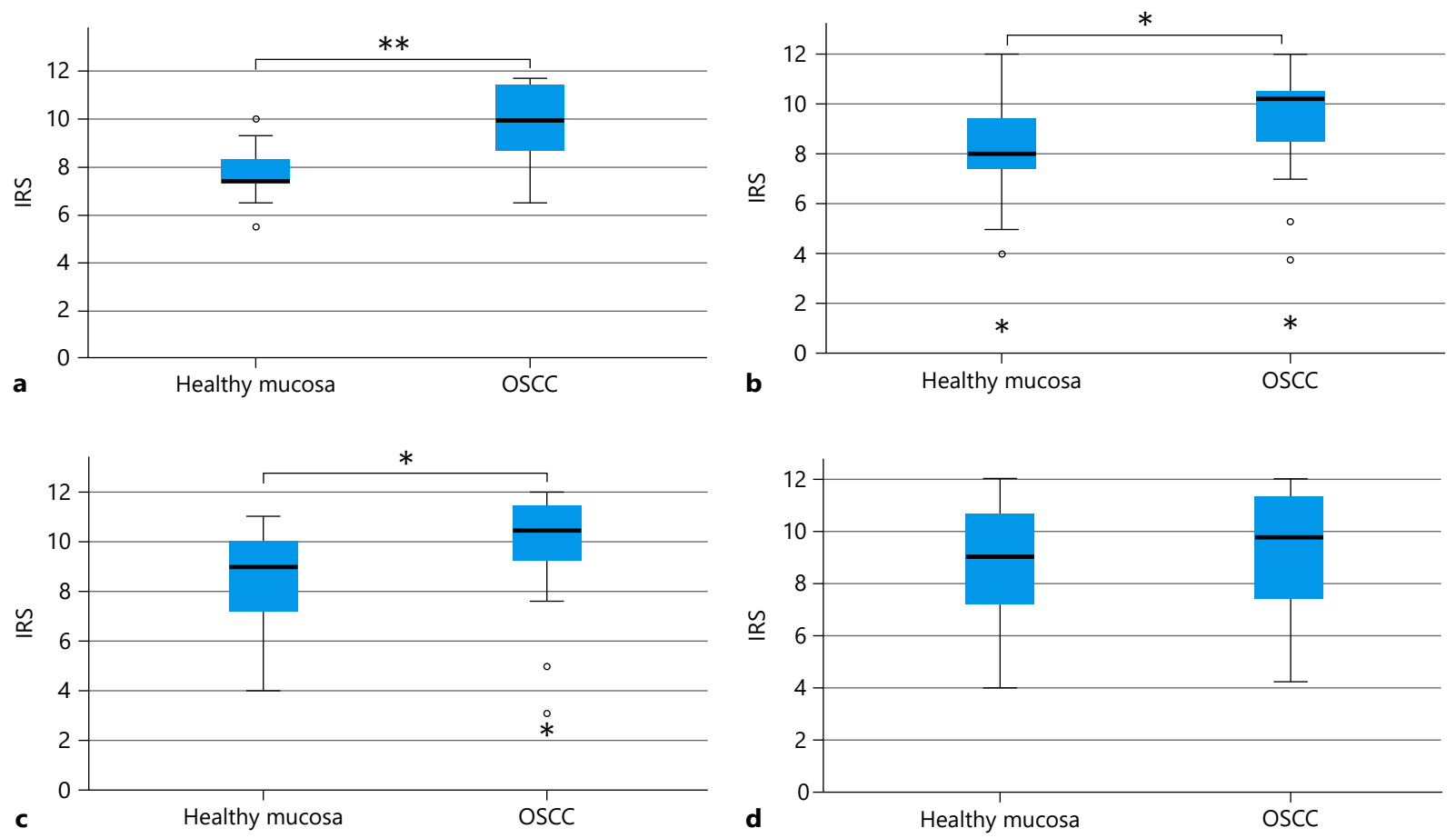

Fig. 1. Boxplot diagrams showing the expression of antibodies against pAKT (a), pERK (b), 3-NT (c), and 8-IP (d) in OSCC and healthy mucosa. The ranges (with 25th and 75th percentiles) are displayed. The medians are shown as a vertical line; extreme values are included. Statistical significance of immunostaining could be observed in $\mathbf{a}, \mathbf{b}$, and $\mathbf{c}$ and is marked by asterisks $\left({ }^{* *} p<0.0 .1{ }^{*} p<0.05\right)$. IRS, immunoreactive score (see text for formula); OSCC, oral squamous cell carcinoma.

mandible $(n=10 ; 33.4 \%)$, tongue $(n=9 ; 30 \%)$, floor of the mouth $(n=7 ; 23.3 \%)$, buccal mucosa $(n=3 ; 10 \%)$, and maxilla $(n=1 ; 3.3 \%)$. All patients were treated with tumor resection and neck dissection ipsilaterally or bilaterally, according to local protocol [Koerdt et al., 2016]. Postoperatively, 10 patients (30\%) had cervical lymph node metastases on histopathological analysis: 5 of which were classified as $\mathrm{pN} 1$ $(50 \%), 3$ as pN2b (30\%), and 2 as pN2c (20\%). Postoperative T-status were as follows: pT1 $(n=4 ; 13.3 \%), \mathrm{pT} 2(n=10$; $30 \%)$, pT3 ( $n=3 ; 10 \%)$, and pT4 $(n=13 ; 46.7 \%)$.

Tissue specimens from the healthy controls were obtained during standard operative procedures. In analogy, 30 patients were included: 17 (56.6\%) were male and 13 (43.4\%) were female. The median age was $60 \pm 12$ years (range: $32-87$ ). Smokers and patients with a pathological consume of alcohol were not included in the control group.

\section{Immunohistochemistry}

The results of immunostaining are displayed in Figure 1 . The expression profiles of pAKT $(9.79 \pm 1.58$ vs.
$7.74 \pm 1.06 ; p<0.01$; Fig. 1a), pERK (9.21 \pm 2.50 vs. 8.07 \pm 2.23 ; $p=0.01$; Fig. $1 \mathrm{~b})$, and $3-\mathrm{NT}(9.61 \pm 2.52$ vs. 8.29 \pm 2.045 ; $p=0.039$; Fig. $1 \mathrm{c}$ ) showed a statistically significant increased expression in OSCC specimens compared to healthy controls. The immunohistochemical expression of 8-IP was also increased in OSCC; however, no significance could be observed in the statistical analysis $(9.31 \pm 2.43$ vs. $8.69 \pm 2.41 ; p=0.302$; Fig. $1 \mathrm{~d}$; all $p$ values were calculated using the Mann-Whitney $\mathrm{U}$ test). Examples of immunostaining according to the statistical analysis are displayed in Figure 2 (microphotographs $2 \mathrm{c}$ and $2 \mathrm{~d}$ show exemplarily positively stained cells, marked by arrows).

\section{RT-PCR}

A significantly increased expression of genes encoding for MAPK1 could be found in RT-PCR for OSCC specimens $(6.76 \mathrm{E}-2 \pm 1.33 \mathrm{E}-1$ vs. $1.02 \mathrm{E}-2 \pm 2.19 \mathrm{E}-2 ; p=0.032$; Fig. 3a). Furthermore, genes for NOS1 (1.08E-2 $\pm 2.11 \mathrm{E}-$ 2 vs. $1.26 \mathrm{E}-3 \pm 5.11 \mathrm{E}-3$; $p=0.025$; Fig. $3 \mathrm{~b}$ ) and NOS 3 

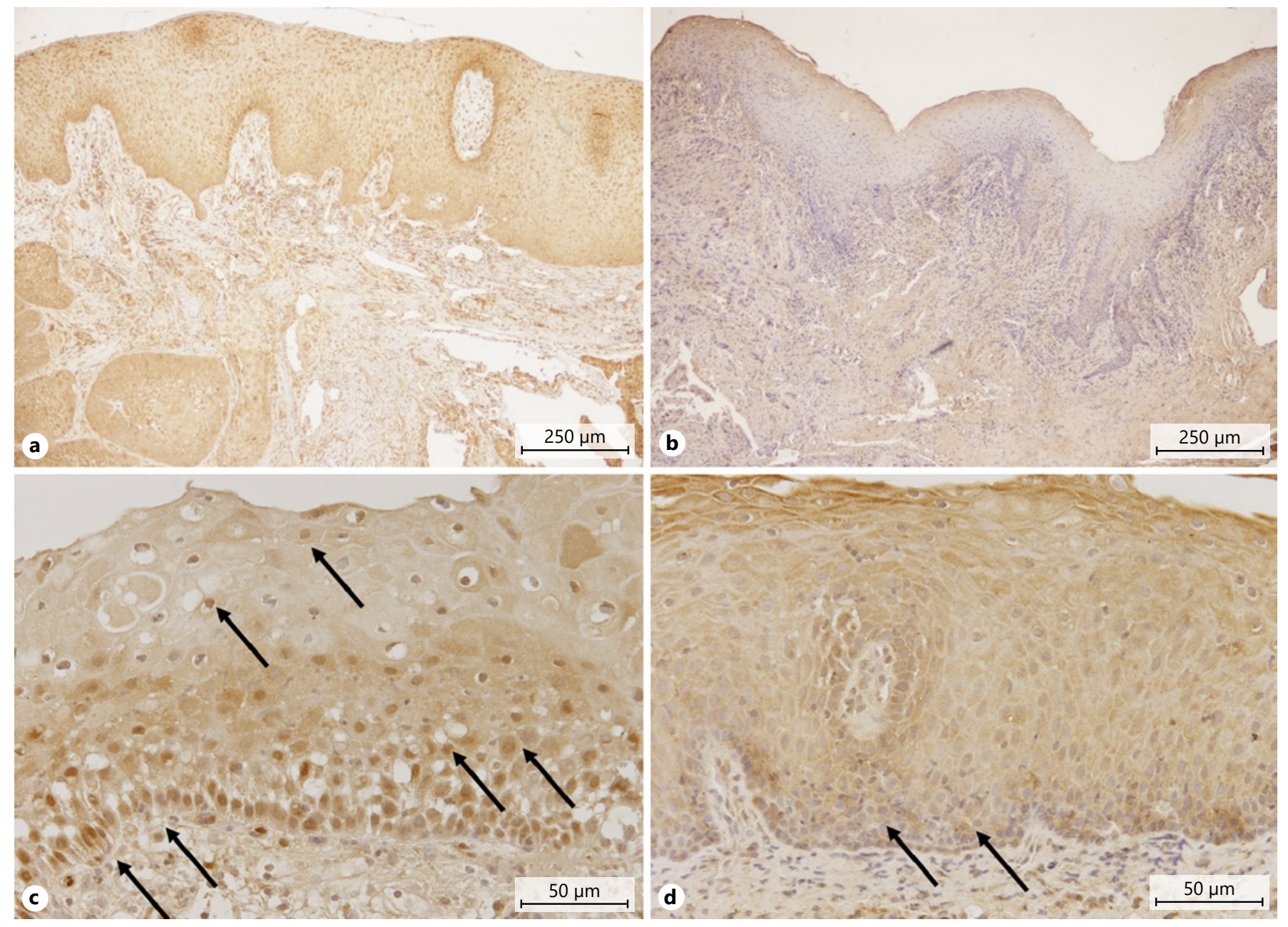

Fig. 2. Overview microphotographs of immunohistochemical staining against pAKT (a) and isoprostane (b; both magnification 40×). Detail microphotographs of staining against pERK (c) and 3-NT (d; both magnification $200 \times$ ) showing positively stained cells. In the detail microphotographs (c, d), exemplarily positively stained cells are marked by arrows.

$(5.60 \mathrm{E}-4 \pm 1.72 \mathrm{E}-3$ vs. $4.98 \mathrm{E}-3 \pm 1.13 \mathrm{E}-2 ; p=0.046$; Fig. $3 c$ ) showed a statistically significant increase in OSCC versus healthy mucosa. Boxplots are displayed in Figure 3. The comparison between tissue specimens from smokers plus patients with alcohol abuse and healthy patients did not reveal statistically significant differences in terms of protein or gene expression.

\section{Discussion}

Oxidative and nitrosative stress induced by RONS is a cofactor in the induction, maintenance, and progression of extensive health burdens such as diabetes, Alzheimer's disease, and solid cancer as they promote chronic inflam- matory conditions and support cell cycle alterations [Nishikawa and Araki, 2007; Reuter et al., 2010]. The characteristics of malignant neoplasm, i.e., with invasive tumor growth, metastatic spread, as well as disease recurrence, are the key factors to limited treatment outcome in patients. The complex network of tumor biology is little understood. As exogenous carcinogens such as tobacco smoke and alcohol induce the exposure of the oral mucosa to toxic RONS, the complex cell-based balancing network of physiological antioxidant mechanisms can be irrecoverably damaged and overpowered. Consequently, cellular defense mechanisms can be overwhelmed, resulting in DNA strand breaks, membrane damages, and damages in tumor suppressor genes and therefore the manifestation of cancer [Johnson, 2001]. 


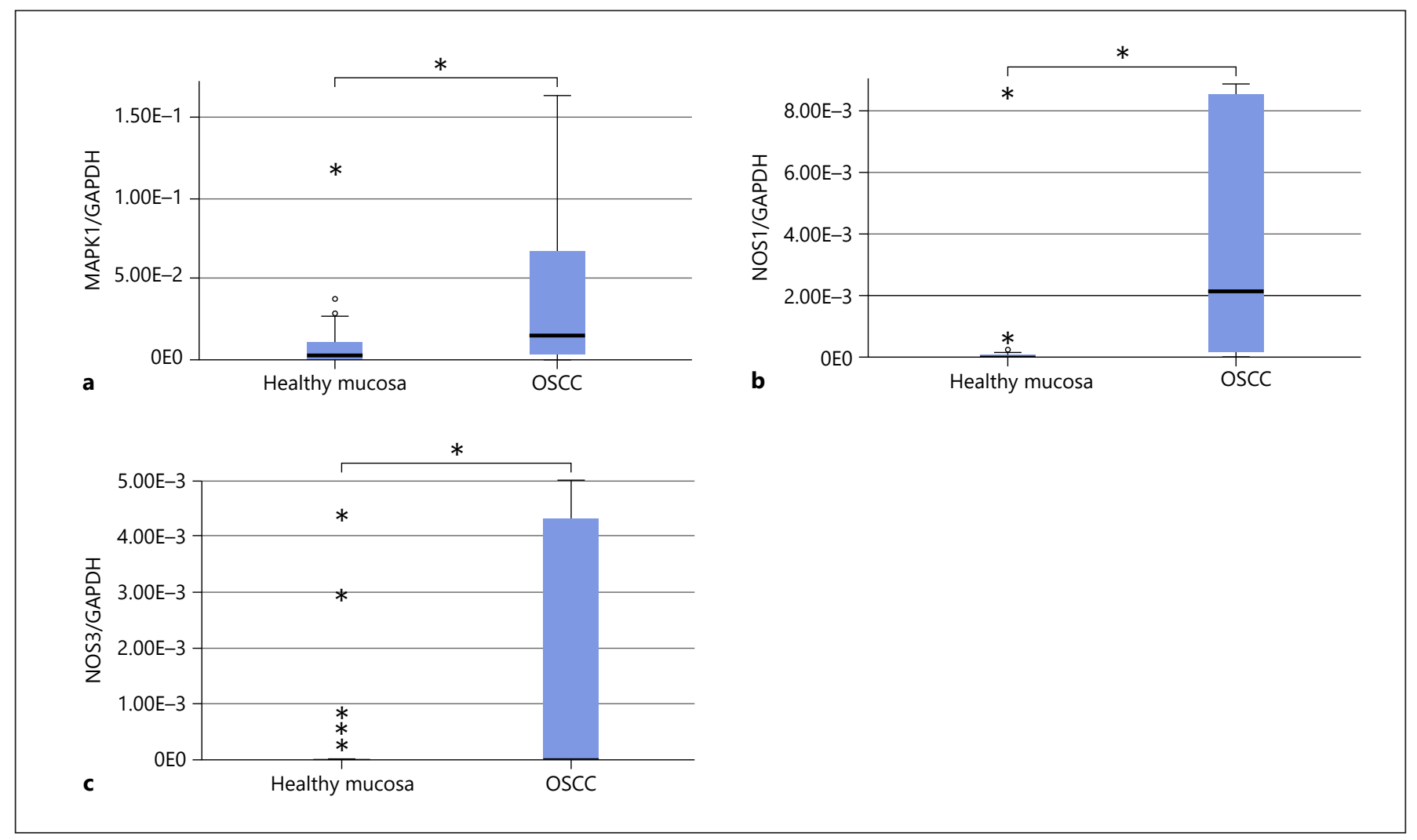

Fig. 3. Boxplot diagrams showing the expression of genes MAPK1 (a), NOS1 (b), and NOS3 (c) in OSCC and healthy mucosa in PCR. The ranges (with 25th and 75th percentiles) are displayed. The medians are shown as a vertical line; extreme values are included. Statistical significance in all expression analysis (a-c) was observed and marked by an asterisk $(* p<0.05)$. NOS, nitric oxide synthase; MAPK, mitogen-activated protein kinase; GAPDH, glyceraldehyde 3-phosphate dehydrogenase; OSCC, oral squamous cell carcinoma.

In concordance with the current study results, a significant overexpression of NOS, 3-NT, and pAKT and a dysregulation of the pERK/MAPK network in OSCC tissue specimens confirm the capacities of the described antibodies and genes in the detection of oxidative and nitrosative stress in OSCC. The influence of NOS and its cofactors plays a major role in primary cell cycle damage, supports tumor angio- and lymphogenesis in dedifferentiated tissue, and facilitates metastatic spread. NO, synthetically provided as an emergency drug in acute coronary syndrome, physiologically induces vessel dilatation and permeability. In tumor growth, NO deviants are released by the dysfunctional tumor vessel endothelium as well as by the solid tumor tissue itself and play a major role in the angiogenic switch [Hanahan and Weinberg, 2011]. Here, NO species serve as promotors of vessel growth and enhance vessel permeability which facilitates the blood and lymphatic transfer of tumor cells to the surrounding tissue [Maeda et al., 1994]. Beside these effects,
RONS induce proliferation pathways such as the pERK/ MAPK pathway and are strongly associated with tumor progression in OSCC [Yang et al., 2015; Kesarwala et al., 2016]. Recent investigations support the influence of pERK on metastatic spread of breast cancer patients as its expression was directly associated with the occurrence of lymph node metastasis [Adeyinka et al., 2002; Steeg, 2003]. With reference to previous publications, RONS are also strongly associated with the occurrence of wound healing disorders after radiation therapy and its induction of inflammation and fibrosis [Koerdt et al., 2017a, b].

The current study shows exemplarily the role of RONS in OSCC. The statistically significant increase in expression of stable degradation products in immunohistochemistry and RT-PCR illustrates this connection. The overexpression of RONS in OSCC, in comparison to healthy specimens, and the used degradation products could act as representatives for detection and possible therapy targets. Further research is essential to under- 
stand the complex network of oral cancer pathology and adjust therapeutic concepts to the patients' benefit. At present, the application of ERK inhibitors to counteract tissue alterations induced by RONS has only been tested in preclinical studies with limited success [Samatar and Poulikakos, 2014].

However, the current study was able to verify RONSspecific antibodies and genes in OSCC tissue in the detection of oxidative and nitrosative stress. Nevertheless, as the number of specimens is comparatively low and cellbased experiments are still owing, intensified research of the individual impact of cancer-associated pathway alterations is needed. Hence, this article provides further insight into the role of oxidative and nitrosative stress in OSCC, specific possible mechanisms of detection, and anticipates supplementary research.

\section{Statement of Ethics}

This study complies with the guidelines for human studies and was conducted ethically in accordance with the World Medical Association Declaration of Helsinki. The Institutional Review Board of the Technical University of Munich (TUM), Germany, approved the study (No. 398/13). All patients have given their written informed consent. The study protocol was approved by the institute's committee on human research.

\section{Conflict of Interest Statement}

The authors have no conflicts of interest to declare.

\section{Funding Sources}

The study was supported by internal funding.

\section{Author Contributions}

S.K. initiated the study. S.K. and G.F. wrote the paper. G.F. and O.L.Z. collected the tissue specimens. O.L.Z. performed all laboratory work. C.M.R. and C.D. did the biometrical statistics. K.K. evaluated the microradiographs of the specimens, H.D., K.-D.W., M.R.K., and M.H. reviewed the paper prior to submission. S.K. submitted the paper. All authors read and approved the final version of the manuscript.

\section{References}

Adeyinka A, Nui Y, Cherlet T, Snell L, Watson $\mathrm{PH}$, Murphy LC. Activated mitogen-activated protein kinase expression during human breast tumorigenesis and breast cancer progression. Clin Cancer Res. 2002 Jun;8(6): 1747-53.

Baker SP, Braver ER, Chen LH, Li G, Williams AF. Drinking histories of fatally injured drivers. Inj Prev. 2002 Sep; 8(3): 221-6.

Chen EY, Mazure NM, Cooper JA, Giaccia AJ. Hypoxia activates a platelet-derived growth factor receptor/phosphatidylinositol 3-kinase/Akt pathway that results in glycogen synthase kinase- 3 inactivation. Cancer Res. 2001 Mar;61(6):2429-33.

Crossthwaite AJ, Hasan S, Williams RJ. Hydrogen peroxide-mediated phosphorylation of ERK1/2, Akt/PKB and JNK in cortical neurones: dependence on $\mathrm{Ca}(2+)$ and $\mathrm{PI} 3$-kinase. J Neurochem. 2002 Jan;80(1):24-35.

Cunningham MJ, Johnson JT, Myers EN, Schramm VL Jr, Thearle PB. Cervical lymph node metastasis after local excision of early squamous cell carcinoma of the oral cavity. Am J Surg. 1986 Oct;152(4):361-6.

Dröge W. Free radicals in the physiological control of cell function. Physiol Rev. 2002 Jan; 82(1):47-95.

El-Habr EA, Tsiorva P, Theodorou M, Levidou G, Korkolopoulou P, Vretakos G, et al. Analysis of PIK3CA and B-RAF gene mutations in human astrocytomas: association with activa- tion of ERK and AKT. Clin Neuropathol. 2010 Jul-Aug;29(4):239-45.

Hanahan D, Weinberg RA. Hallmarks of cancer: the next generation. Cell. 2011 Mar; 144(5): 646-74.

Johnson N. Tobacco use and oral cancer: a global perspective. J Dent Educ. 2001 Apr;65(4): 328-39.

Kesarwala AH, Krishna MC, Mitchell JB. Oxidative stress in oral diseases. Oral Dis. 2016 Jan; 22(1):9-18

Koerdt S, Siebers J, Bloch W, Ristow O, Kuebler AC, Reuther T. Role of oxidative and nitrosative stress in autogenous bone grafts to the mandible using guided bone regeneration and a deproteinized bovine bone material. J Craniomaxillofac Surg. 2014 Jul;42(5):560-7.

Koerdt S, Röckl J, Rommel N, Mücke T, Wolff KD, Kesting MR. Lymph node management in the treatment of oral cancer: analysis of a standardized approach. J Craniomaxillofac Surg. 2016 Oct;44(10):1737-42.

Koerdt S, Tanner N, Rommel N, Rohleder NH, Frohwitter G, Ristow O, et al. NOS1-, NOS3-, PIK3CA-, and MAPK-pathways in skin following radiation therapy. Biomark Res. 2017a Jan;5(1):3.

Koerdt S, Tanner N, Rommel N, Rohleder NH, Stoeckelhuber M, Wolff KD, et al. An Immunohistochemical Study on the Role of Oxidative and Nitrosative Stress in Irradiated Skin. Cells Tissues Organs. 2017b;203(1):12-9.
Lehnig M. Radical mechanisms of the decomposition of peroxynitrite and the peroxynitrite$\mathrm{CO}(2)$ adduct and of reactions with L-tyrosine and related compounds as studied by (15) $\mathrm{N}$ chemically induced dynamic nuclear polarization. Arch Biochem Biophys. 1999 Aug; 368(2):303-18.

Lingen MW, Kalmar JR, Karrison T, Speight PM. Critical evaluation of diagnostic aids for the detection of oral cancer. Oral Oncol. 2008 Jan; 44(1):10-22.

Maeda H, Noguchi Y, Sato K, Akaike T. Enhanced vascular permeability in solid tumor is mediated by nitric oxide and inhibited by both new nitric oxide scavenger and nitric oxide synthase inhibitor. Jpn J Cancer Res. 1994 Apr; 85(4):331-4.

Mohiuddin I, Chai H, Lin PH, Lumsden AB, Yao Q, Chen C. Nitrotyrosine and chlorotyrosine: clinical significance and biological functions in the vascular system. J Surg Res. 2006 Jun; 133(2):143-9.

Nishikawa T, Araki E. Impact of mitochondrial ROS production in the pathogenesis of diabetes mellitus and its complications. Antioxid Redox Signal. 2007 Mar;9(3):343-53.

Remmele W, Schicketanz KH. Immunohistochemical determination of estrogen and progesterone receptor content in human breast cancer. Computer-assisted image analysis (QIC score) vs. subjective grading (IRS). Pathol Res Pract. 1993 Sep;189(8):862-6. 
Reuter S, Gupta SC, Chaturvedi MM, Aggarwal BB. Oxidative stress, inflammation, and cancer: how are they linked? Free Radic Biol Med. 2010 Dec;49(11):1603-16.

Samatar AA, Poulikakos PI. Targeting RAS-ERK signalling in cancer: promises and challenges. Nat Rev Drug Discov. 2014 Dec;13(12):92842.

Schulze A, Lampert T. Bundes-Gesundheitssurvey: Soziale Unterschiede im Rauchverhalten und in der Passivrauchbelastung in Deutschland. Berlin: Robert-Koch-Institut; 2006.

Skinner KA, Crow JP, Skinner HB, Chandler RT, Thompson JA, Parks DA. Free and protein-associated nitrotyrosine formation following rat liver preservation and transplantation. Arch Biochem Biophys. 1997 Jun;342(2):282-8.

Steeg PS. Metastasis suppressors alter the signal transduction of cancer cells. Nat Rev Cancer. $2003 \mathrm{Jan} ; 3(1): 55-63$.

Talamini R, Bosetti C, La Vecchia C, Dal Maso L, Levi F, Bidoli E, et al. Combined effect of tobacco and alcohol on laryngeal cancer risk: a case-control study. Cancer Causes Control. 2002 Dec;13(10):957-64.

Tasioudi KE, Saetta AA, Sakellariou S, Levidou G, Michalopoulos NV, Theodorou D, et al. pERK activation in esophageal carcinomas: clinicopathological associations. Pathol Res Pract. 2012 Jul;208(7):398-404.
Valko M, Leibfritz D, Moncol J, Cronin MT, Mazur M, Telser J. Free radicals and antioxidants in normal physiological functions and human disease. Int J Biochem Cell Biol. 2007;39(1): 44-84.

Yang L, Wang Y, Guo L, Wang L, Chen W, Shi B. The expression and correlation of iNOS and p53 in oral squamous cell carcinoma. Biomed Res Int. 2015;2015:637853.

Zeng G, Nystrom FH, Ravichandran LV, Cong LN, Kirby M, Mostowski H, et al. Roles for insulin receptor, PI3-kinase, and Akt in insulin-signaling pathways related to production of nitric oxide in human vascular endothelial cells. Circulation. 2000 Apr;101(13):1539-45. 